\title{
A Hybrid Intelligent Model for Urban Seismic Risk Assessment from the Perspective of Possibility and Vulnerability Based on Particle Swarm Optimization
}

\author{
Jinlong Chu, ${ }^{1,2}$ Qiang Zhang, ${ }^{1}$ Ai Wang $\mathbb{D}^{1,2}$ and Haoran Yu ${ }^{1,2}$ \\ ${ }^{1}$ School of Architecture and Planning, Anhui Jianzhu University, Hefei 230022, China \\ ${ }^{2}$ Anhui Urbanization Development Research Center, Hefei 230022, China \\ Correspondence should be addressed to Ai Wang; 296712074@qq.com
}

Received 22 October 2021; Revised 9 November 2021; Accepted 16 November 2021; Published 7 December 2021

Academic Editor: Punit Gupta

Copyright (C) 2021 Jinlong Chu et al. This is an open access article distributed under the Creative Commons Attribution License, which permits unrestricted use, distribution, and reproduction in any medium, provided the original work is properly cited.

\begin{abstract}
Assessing seismic risk is an essential element of urban risk management and urban spatial security work. In response to the issues posed by the complexity and openness of urban systems, the nonlinearity of driving factors, and sudden changes in geological processes that affect urban seismic research, this paper is based on a variety of intelligent algorithms to develop a hybrid intelligent model that integrates probability and vulnerability to evaluate and quantify the difference in the urban spatial units distribution of earthquake risk. We applied this model to Hefei, one of the few superlarge provincial capital cities on the "Tancheng-Lujiang" fault zone, one of the four major earthquake zones in China, which suffers frequent earthquakes. Our method combined the genetic algorithm (GA), particle swarm optimization (PSO), and backpropagation neural network methods (BP) to automatically calculate rules from inputted data on known seismic events and predict the probability of seismic events in unknown areas. Then, based on the analytic hierarchy process (AHP), spatial appraisal and valuation of environment and ecosystems method (SAVEE), and EMYCIN model, an urban seismic vulnerability was evaluated from the four perspectives of buildings, risk of secondary disasters, socioeconomic conditions, and urban emergency response capabilities. In the next step, the overall urban seismic risk was obtained by standardizing and superimposing seismic probability and vulnerability. Using the hybrid intelligent model, earthquake probability, seismic vulnerability, and overall seismic risk were obtained for Hefei, and the spatial characteristics of its overall seismic risk were examined. This study concludes that areas with very high, high, low, and very low earthquake risk in Hefei account for $8.10 \%, 31.90 \%, 40.94 \%$, and $19.06 \%$ of its total area, respectively. Areas with very high earthquake risk are concentrated in the old city, the government affairs district, Science City, and Xinzhan District. This study concludes that government authorities of Hefei should target earthquake safety measures consisting of basic earthquake mitigation measures and pre- and postearthquake emergency measures. In the face of regional disasters such as earthquakes, coordinating and governing should be strengthened between cities and regions.
\end{abstract}

\section{Introduction}

The Center for International Earth Science Information Network of Columbia University found that 450 of the world's 633 megacities are exposed to at least one disaster risk [1]. Earthquakes, which occur suddenly and are hugely destructive, involve a series of chain reactions, resulting in secondary disasters and induced seismicity [2-4]. They seriously impact the development of cities and the safety of urban residents. China is located at the intersection of the circum-Pacific and Alpide seismic belts, which means it is subject to highly frequent and intense seismic activity. China accounts for $7 \%$ of the world's landmass, but it has the most severe earthquakes in the world, having suffered $33 \%$ of the world's recorded strong earthquakes $[5,6]$. With the acceleration of urbanization in China, urban economic output and structures are becoming increasingly complex, which means urban seismic risk is increasing exponentially [7, 8]. Strengthening our ability to appraise the overall risk of urban seismic activity and explore the spatial characteristics of that risk holds important practical significance for determining the social and economic impacts of earthquake damage, 
improving resilience in urban construction, and achieving sustainable urban development.

Due to the nonlinear nature of earthquake related factors and the complexity of geological processes, seismic research has long been an important and active topic among scholars $[9,10]$. Past research has largely focused on analyzing the probability of earthquake occurrence and assessing the vulnerability of cities to earthquakes and the overall earthquake risks.

(1) Analyzing probability to earthquake: After the establishment of the California Earthquake Authority in 1994, the UCERF3 earthquake rupture forecast model was built, which has been continuously optimized and upgraded since. It integrates the time independent model for calculating long-term seismicity, the time-dependent model for calculating the probability of an earthquake considering the elapsed time since an earthquake, and the epidemic-type aftershock sequence spatiotemporal cluster model $[10,11]$. Due to the shortcomings of the UCERF3 model, other scholars have researched earthquake probability forecasting. For example, Wang et al. (2019) calculated the long-term occurrence rate of earthquakes of different magnitudes by collecting seismic geology, geodesy, and seismology data in the Sichuan-Yunnan area [12]. Khan et al. (2018) proposed a practical event-based probabilistic seismic hazard assessment method that uses data on measured seismicity, available historical seismicity, and geological structure to simulate and predict the probability of earthquakes in regions where limited data is available [13]. Murray et al. (2015) proposed a new deep learning method called Focal Mechanism Network, which learns global waveform characteristics from theoretical data to predict the source focal mechanism [14]. Alarifi et al. (2012) proposed the application of an artificial intelligence prediction system to predict the magnitude and probability of earthquakes in various regions through adjustments to the neural network structure and different configurations of parameters [15].

(2) Assessing vulnerability to earthquakes: Earthquake vulnerability refers to the vulnerability of a city's society, economy, and physical environment to seismic activity [16, 17] (Rashed et al., 2003; Han et al., 2021). Noriega et al. (2012) explored the variations in demographics and socioeconomic characteristics associated with earthquake losses taking into consideration natural systems, the socioeconomic system, the built environment, and geospatial processes [18]. Joseph and Jacquleen (2013) constructed a seismic vulnerability assessment model of urban spatial, social, and economic systems [19]. After comparing the limitations of the different evaluation methods, Khan (2012) proposed a method to explore internal factors and mechanisms of earthquake vulnerability and, based on this, proposed relative solutions [20]. Mosen et al. (2018) on the other hand used Analytical Network Process (ANP) and Artificial Neural Network (ANN) models to construct a vulnerability index to measure the vulnerability of urban social and economic systems, geological conditions, and physical environments [21].

(3) In disciplines such as economics, engineering, and disaster science, the definition of risk mainly focuses on the possibility and consequences of a disaster $[22,23]$. Therefore, the risk of an earthquake can be represented by the expected value of consequences, that is, the probability and scope of the occurrence of an earthquake, and whether the earthquake's intensity will exceed a city's safety threshold [24]. Based on analysis of the randomness and intensity of earthquakes, Zhong and $\mathrm{Yu}$ proposed a method of predicting earthquakes as a fuzzy random event [25]. Davidson et al. proposed the earthquake disaster risk index, which can measure the earthquake disaster risk in major cities and describes the relative contributions of various factors to overall earthquake risk [26]. Jena et al. (2020) developed an integrated model using the artificial neural network-hierarchy process (ANN-AHP) model to quantify urban population caused by impending earthquakes [27]. Mili et al. (2018) developed a model for assessing urban earthquake risk based on probability, vulnerability, and response capacity to explain the safety level of urban structures about earthquakes and assess the impacts of preventive measures on risk [28].

Scholars have conducted useful research on seismic risk, using various methods and models, including mathematical modeling, spatial analysis, and quantitative evaluation. Given the complexity and openness of urban systems, the nonlinearity of driving factors, and sudden changes that can occur to geological processes, however, existing models and algorithms, as well as assessment methods, need to be more rigorous. As for the measurement and quantification of earthquake risk, it is affected by different disciplines and the scale of the research object. Its evaluation indicators are limited to the level of regional elements, engineering facilities, or building units, without considering the interinfluencing factors at different scales, mutual feedback relationship. In particular, quantify the level of earthquake risk unilaterally based on the probability of earthquake occurrence or vulnerability assessment.

Because of this, this paper proposes a hybrid intelligent model and empirically applied it to Hefei, one of the few superlarge provincial capital cities on the "TanchengLujiang" fault zone, one of the four major earthquake zones in China. Multiscale nested evaluation indicators and models are constructed from the three scales of Hefei City area, central city area, and block, as well as possibility and vulnerability. The model is based on the existing evaluation path system in the existing disaster science, urban management, computer engineering, and other disciplines $[29,30]$. It combines the perspectives and advantages of 
multiple disciplines and is more targeted and adaptable to the complex nonlinearities of earthquakes. The hybrid intelligent model includes three aspects: First is to create a better GA-PSO-BP neural network model to predict the possibility of earthquakes by automatically calculating rules from data on known earthquake events to forecast earthquakes in unknown areas. Second, given the complex nonlinear characteristics of urban seismic vulnerability, an AHP-SAVEE-EMYCIN integrated algorithm is introduced to evaluate vulnerability to earthquake damage from four aspects: building vulnerability, risk of secondary disasters, socioeconomic vulnerability, and urban emergency response capabilities. In the next step, the overall urban seismic risk was obtained by standardizing and superimposing seismic probability and vulnerability. Third, the possibility of earthquake and the vulnerability of earthquake damage are unified and standardized to obtain the comprehensive urban earthquake risk, and the difference in the distribution of earthquake risk in urban spatial units is discussed, which provides new ideas for earthquake risk assessment and earthquake prevention management.

\section{Materials and Methods}

2.1. Study Area. Hefei is the provincial capital of Anhui Province. The city has experienced sustained social and economic development thanks to rapid urbanization, optimization of its industrial structure, and continuous infrastructure construction. Between 2009 and 2019, Hefei's urbanization rate and GDP growth rate both ranked first in China. Population growth and improvements to its industrial structure and infrastructure have promoted the peripheral expansion of the city, and Hefei's urban framework has continued to expand. Urban space has expanded from a small circle around the city and three wings to a multicenter city cluster, with an increasingly complex economy [31]. Hefei's rapid development has elevated it from among the middle and lower ranks of Chinese provincial capitals to among the top ten most successful, becoming a subcenter of the Yangtze River Delta City Cluster and home to one of China's four comprehensive national science centers.

Hefei is located in the hilly region between the Yangtze and Huai rivers, which is a complex geological environment [32]. The Tancheng-Lujiang fault zone in which Hefei City is located is the largest fault zone in eastern China, spanning 2,400 km of central Anhui Province (Figure 1(a)). The fault zone has undergone intensive transformations as a result of many tectonic movements over a long period and across a large area, leading to its current complex structural pattern. The Tancheng-Lujiang fault zone has experienced one earthquake of magnitude 8.5 , six earthquakes of magnitude 7 or higher, and three earthquakes of magnitude 5 or higher in Anhui Province, as well as frequent smaller earthquakes. Hefei and its surrounding areas entered a new period of seismic activity in the 1990s. In 1996 and 2006, the State Council identified Hefei as a key national earthquake monitoring and defense city and noted that Hefei faces a great threat from earthquakes [33]. Because of the rapid development of Hefei and its location in the Tancheng-
Lujiang fault zone, the city must pay attention to the danger of earthquakes. This paper selects the city of Hefei as its study area (Figure 1(b)), with the aim of comprehensively and systematically assessing the risk of an earthquake disaster and providing important support for improving the city's disaster prevention and mitigation capabilities, improving urban resilience, and building a high-quality human settlement.

2.2. Materials. The research data for this study largely relates to two areas: earthquake disasters and urban earthquake vulnerability. Hefei's earthquake disaster data consists of information on historical earthquakes, topography, and tectonics. The historical earthquake information includes the location and alignment of faults and the time, location, and magnitude of previous earthquakes. This is taken from the website of the Hefei Geological Bureau (http://dzj.hefei.gov. $\mathrm{cn}$ ), and ArcGIS was used to carry out Euclidean distance analysis and kernel density analysis on seismic points and fault zones, giving the distribution of historical earthquakes in Hefei. Urban topography data is mainly from the geospatial data cloud (http://www.gscloud.cn), with analysis of slope and aspect in the elevation data revealing the topography of Hefei. Plate tectonic information includes peak ground acceleration (PGA) and rock and soil stability, which is obtained from the China Earthquake Administration (https://www.cea.gov.cn).

Earthquake vulnerability data includes building conditions, location of secondary disasters, socioeconomic conditions, and urban emergency response capabilities. Data on building conditions includes the profiles and heights of buildings in 2020 obtained from Baidu Maps, as well as building structures and ages obtained from historical satellite images and on-site investigations. Secondary disaster data mainly consists of information on floods, fires, pollutant leakages, and landslides caused by earthquakes. Data on fires and pollution sources are mainly from obtaining the geographic coordinates of gas stations, chemical plants, and heavily polluting factories and then performing Euclidean distance analysis. Data on flood disasters is based on the danger posed by large reservoirs on the north side of Hefei and low-lying places along rivers, which was combined with digital elevation models and reservoir water capacity information to conduct flood inundation analysis. Landslide data is based on the analysis of areas with a slope greater than $20^{\circ}$. Socioeconomic conditions include population distribution and economic strength. Population data is based on the number of people in each city district and total building area taken from the Hefei Statistical Yearbook, which was used to deduce overall population distribution. The distribution of the vulnerable population is based on Euclidean distance analysis of nursing homes, primary and middle schools, and elderly apartments using Python. Economic intensity is measured using NPP-VIIRS nighttime light data. Light data is from the Group on Earth Observations, with noise reduction performed and monthly data for 2020 combined into composite annual images. The city's emergency response capability is mainly based on the number of 


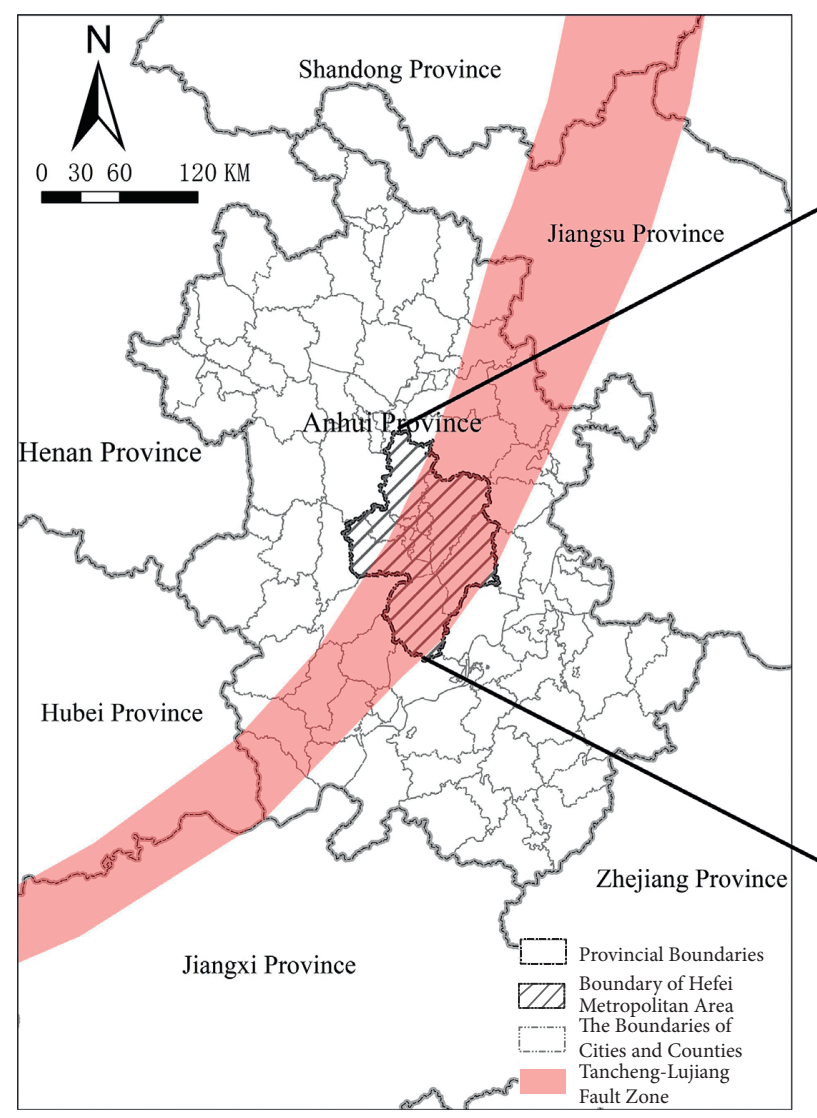

(a)

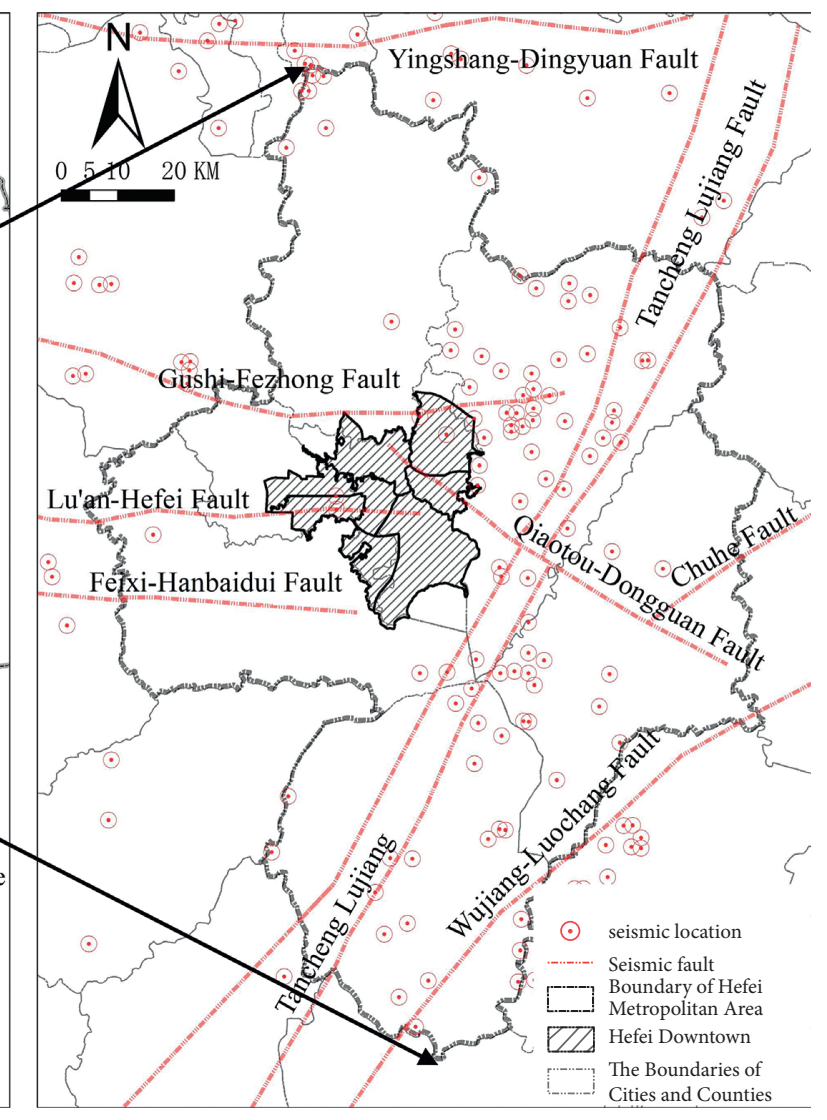

(b)

Figure 1: The location and earthquake situation of the study area. (a) Anhui Province; (b) Hefei metropolitan area.

fire stations, hospitals, and shelters it has. This data was used to gather geographic coordinates using Baidu Maps. After collecting data on earthquake disasters and urban seismic vulnerability, preprocessing including vectorization, standardization, and normalization of relevant data was completed using ArcGIS to create an earthquake disaster database.

\section{Methods}

3.1. A Hybrid Intelligent Model. Given the complexity and openness of urban systems, the nonlinearity of driving factors, and sudden changes in geological processes involved in urban seismic research $[10,34]$, this paper develops a hybrid intelligent model that integrates probability and vulnerability by integrating multiple intelligent algorithms (Figure 2).

The probability of urban seismic activity was evaluated based on the GA-PSO-BP neural network model. The main steps were as follows: First, seismic probability research in China and overseas was systematically sorted, selecting data in the three areas of earthquake history, topography, and geology. Data was then collected, vectorized, and preprocessed to create an earthquake disaster database for Hefei. The study area was divided into grids using ArcGIS, and the values of various factors were extracted to grid points to establish a data set. Based on historical seismic data, four known points of very high, high, low, and very low seismic probability were identified and imported into MATLAB as initial samples. Repeated training and simulation of the GA-PSO-BP integrated model were conducted and laws were automatically obtained from known earthquake events that could predict the probability of earthquakes in other areas. Finally, we simulated the probability of earthquakes in the entire study area.

An urban seismic vulnerability was evaluated using the AHP-SAVEE-EMYCIN method. The main steps were as follows: (1) Indicators that reflect the essential characteristics of vulnerability, such as the state of urban buildings, the risk of secondary disasters, socioeconomic conditions, and urban emergency response capabilities were selected, collected, and preprocessed to establish the Hefei earthquake disaster vulnerability database. (2) Based on the AHP method, an evaluation system from the perspective of vulnerability influencing factors and evaluation objectives was established, and the average weights of several experts were calculated. (3) The SAVEE algorithm was applied to standardize the value of factors and convert all values to between -1 and 1. (4) Using the EMYCIN formula, an evaluation result of urban seismic vulnerability was obtained by combining the value of influencing factors. Finally, the urban seismic probability and urban seismic vulnerability results were normalized and superimposed to obtain the final urban seismic risk result. 


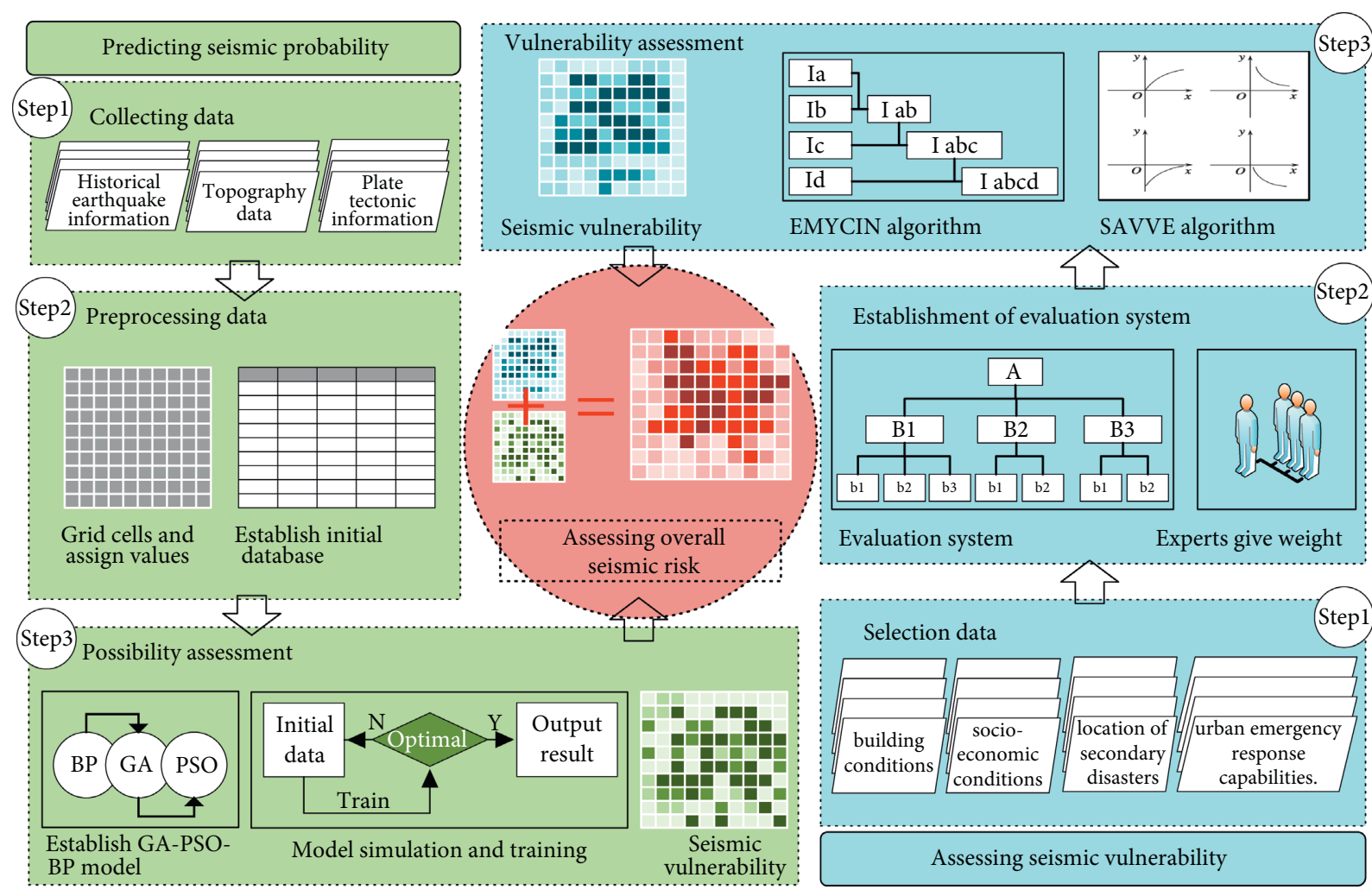

FIgURE 2: Research method.

\subsection{Forecasting Model of Seismic Probability Based on GA- PSO-BP}

3.2.1. Algorithms. Earthquakes are huge, complex systems, and the relationship between each influencing factor is intricate, with extremely significant spatial nonstationarity. The backpropagation (BP) neural network model is a nonlinear dynamic system with strong nonlinear mapping ability, high fault tolerance and robustness, and a strong ability to deal with nonlinear problems. Using the BP neural network algorithm, laws are automatically generated from the entered data of known earthquake events, and the possibility of earthquakes in other areas can be predicted based on quantitative analysis of those laws as well as statistics and probability theory, which avoids errors caused by human predictions of seismic events [35]. Particle Swarm Optimization (PSO) is a population-based stochastic optimization technique in which population particles continuously evolve to find their optimal position and speed [36]. A genetic algorithm (GA) is an iterative optimization algorithm for solving search problems [37]. GA converts spatial parameters of a problem into strings of binary digits called chromosomes and performs techniques inspired by natural evolution, such as selection, inheritance, crossover, and mutation, using an iterative method to evaluate the quality of chromosomes in the new population and finally screen the best chromosomes.

The learning process of the BP algorithm involves optimization and learning the two types of parameters of network connection weights and thresholds. If the initial BP parameters are not properly selected, the BP algorithm can fall into a local optimal solution, and the default gradient descent iterative algorithm tends to slow the convergence speed of the neural network. This study used the mapping ability of the BP neural network in a nonlinear model and combines the learning ability of the GA and PSO-optimized parameter models to create an integrated GA-PSO-BP algorithm (Figure 3). The integrated algorithm uses GA to determine the initial parameters of the BP network and uses PSO to change the connection weights and thresholds in the training iterations, thereby accelerating the convergence speed of the network.

$$
\begin{aligned}
\mathrm{VC}_{i d}= & w^{*} \mathrm{VC}_{i d}+C_{1} \operatorname{rand}_{1}\left(P_{i d}-Z_{i d}\right) \\
& +C_{2} \operatorname{rand}_{2}\left(P_{g d}-Z_{g d}\right), \\
Z_{i d}(t+1)= & Z_{i d}(t)+V C_{i d}(t+1) .
\end{aligned}
$$

\subsubsection{Algorithm Steps}

(1) Collecting and preprocessing data: In terms of influencing factors and assessment objectives of earthquake probability, we selected data from the three areas of seismic history, topography and geomorphology, and tectonics. Historical seismic data includes fault zone density, fault zone distance, earthquake density, and distance to the epicenter. Given the prolific nature of earthquakes, seismic activity is likely to occur repeatedly near the epicenter [38]. Topography and geomorphology, including elevation, slope, and tortuosity, are closely 


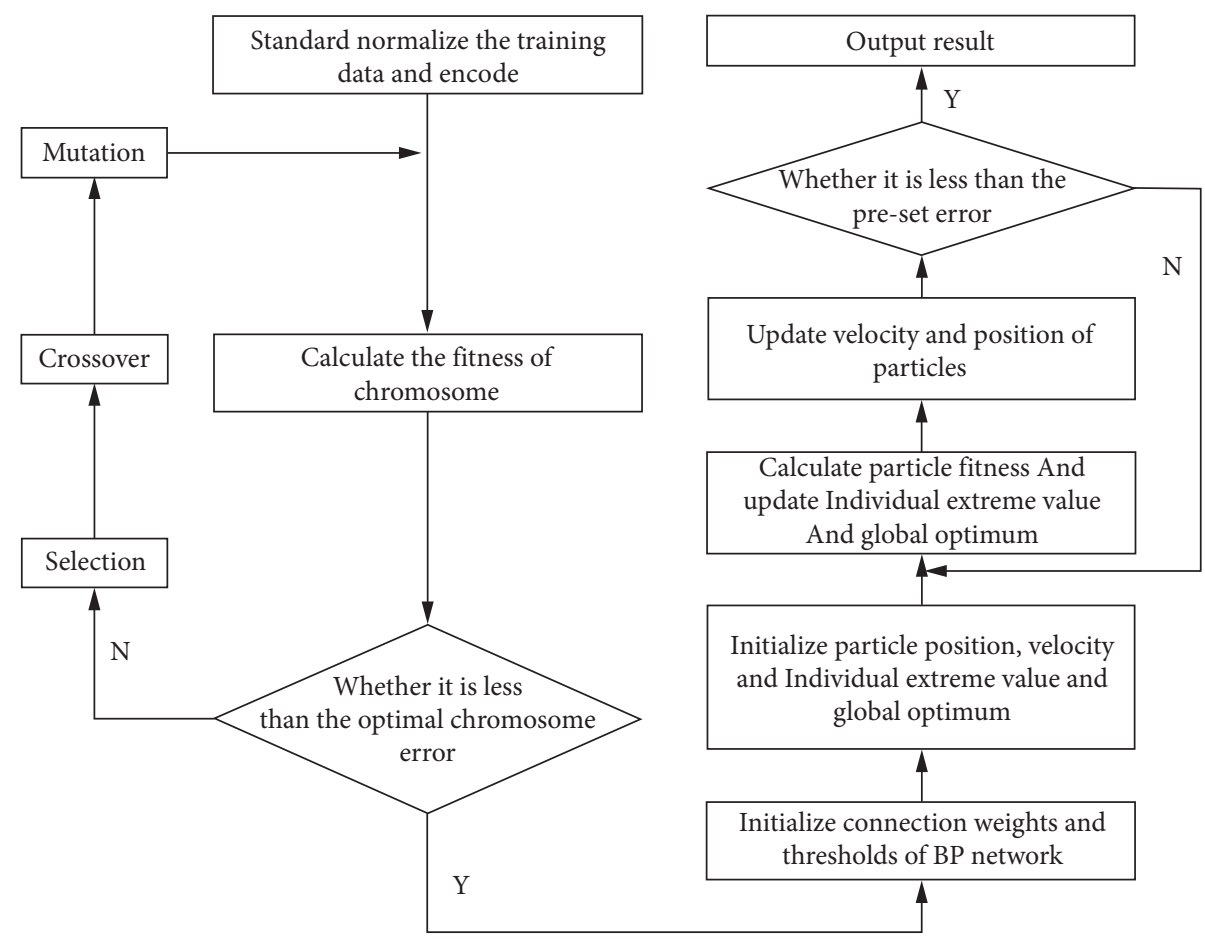

FIgUre 3: Operational flowchart of GA-PSO-BP.

related to earthquake disasters and are the main causes of secondary geological disasters [39]. Tectonics include peak ground acceleration and rock and soil stability, which reflect the exposure of cities to earthquakes and are the material basis for determining the development of earthquakes [38, 40]. ArcGIS created a grid and extracted various standardized factor values. Four known probability points (very high, high, low, and very low) were selected from historical seismic data and imported into MATLAB as the initial sample.

(2) Determining the structure of the initialized BP neural network: The next step is to determine the number of neurons in the input layer, hidden layer, and output layer. Nine neural units $x 1-x 9$ were set as the input layer $n$, corresponding to nine influencing factors, including the density of the fault, distance from the fault, earthquake density, distance from the epicenter, stability of rock and soil, and elevation. The output layer $m$ was set as four neural units $y 1-y 4$, corresponding to the four levels of earthquake probability: very high, high, low, and very low.

(3) Calculating the initial connection weights and thresholds based on GA: After GA model training, maximum personal accommodation can be determined. Each component is then decoded into corresponding parameters, that is, the initial connection weights and thresholds of the network. It is then determined whether optimal fitness has been reached. If it is reached, the chromosome undergoes related calculations in the next step; otherwise, further selections, crossovers, and mutations are performed.
(4) Using PSO to calculate optimal connection weights and thresholds: In the iterative process, PSO is used to update the initial connection weights and thresholds obtained in the third step. Using the PSO algorithm, we set the population size to 30 and the maximum number of iterations to 100 . Determine whether the new particle swarm generated by the iteration has reached optimal fitness to determine whether the algorithm has reached the preset error or reached the maximum number of iterations. If optimal fitness is reached, the global optimal solution is generated, and the simulation result of the probability of an earthquake in Hefei is obtained. The relevant formulas involved in the calculation process are as follows.

Fitness function: This affects the convergence speed of the genetic algorithm and judges whether the optimal solution is reached, wherein $E_{t}$ is the sum of the errors of each unit, $C_{k}^{t}$ is the actual output, $y_{k}^{t}$ is the target output, and $T$ is the number of test samples. The smaller the value of the objective function, the larger the fitness function.

$$
\begin{aligned}
E_{t} & =\frac{1}{2} \sum_{k=1}^{m}\left(C_{k}^{t}-y_{k}^{t}\right)^{2}, \\
E & =\frac{1}{2} \sum_{t=1}^{T} \sum_{k=1}^{m}\left(C_{k}^{t}-y_{k}^{t}\right)^{2} \\
& =\sum_{t=1}^{T} E_{t} .
\end{aligned}
$$


Designing the crossover operators: The two crossover operators are set as $h_{A}^{i}$ and $h_{B}^{i}$, and crossover operations are performed on them, and two new individual sums $h_{A}^{(i+1)}$ and $h_{B}^{(i+1)}$ are created; $a$ is random number distributed between 0 and 1 .

$$
\begin{aligned}
& h_{A}^{(i+1)}=a h_{B}^{i}+(1-a) h_{A}^{i}, \\
& h_{B}^{(i+1)}=a h_{A}^{i}+(1-a) h_{B}^{i} .
\end{aligned}
$$

Designing the mutation operator: The mutation operator adopts a unified mutation strategy. Set an individual to $H=h_{1} h_{1} \ldots h_{k} h_{j}$, wherein $h_{k}$ is the mutation point, and its value range is $\left(H_{\text {man }}^{k}-H_{\text {min }}^{k}\right)$. After uniform mutation of $\mathrm{H}$ at this mutation point, a new individual $H=h_{1} h_{1} \ldots h_{k}^{\prime} h_{j}$ is obtained. The new gene value of the mutation point is $h_{k}^{\prime}$, where $\beta$ is a random number distributed between 0 and 1 .

$$
h_{k}^{\prime}=H_{\min }^{k}+\beta\left(H_{\operatorname{man}}^{k}-H_{\min }^{k}\right) \text {. }
$$

Update the velocity and position of the particles: XX and $\mathrm{XX}$ are the speed and position of the particles, respectively, which represent the best position of each particle, and rand() is a random number between $(0,1)$.

\subsection{Urban Seismic Vulnerability Measurement Model Based on AHP-SAVEE-EMYCIN}

3.3.1. Relevant Algorithms. The analytic hierarchy process (AHP) is a multiobjective decision-making analysis method that combines qualitative and quantitative analysis. It can help decision-makers observe and analyze problems and goals. It is widely used in urban operation management, disaster risk analysis, site selection, and other applications $[41,42]$. The spatial appraisal and valuation of environment and ecosystems (SAVEE) methodology is a comprehensive method of evaluating value from multiple perspectives, which can reflect the influences of multiple driving factors. It features simple measurement analysis and strong operability. It is widely used in many fields, such as land valuing, landscape ecology, and natural resource planning $[43,44]$. The EMYCIN algorithm is a model used to iteratively calculate the value of influencing factors and is an extension of reasoning under uncertainty based on the concepts and practical methods of probability theory [41]. Urban seismic vulnerability refers to the overall impact of an earthquake's intensity exceeding the safety threshold that the city can bear, which involves multidimensional influences such as the natural environment, engineering conditions, and social and economic activities.

Due to the spatial imbalance of urban seismic vulnerability, this article attempts to build an AHP-SAVEEEMYCIN integrated model that combines the AHP, SAVEE, and EMYCIN formulas. The integrated algorithm uses the AHP method to establish the evaluation system and index weights, the SAVEE algorithm to standardize the values of influencing factors, and the EMYCIN calculation to superimpose the roles of various factors to obtain seismic vulnerability.

\subsubsection{Calculation Steps}

(1) Establish an evaluation system: Having studied previous seismic research by Chinese and overseas scholars, we selected evaluation indicators that reflect the essential features of seismic vulnerability and created a logical evaluation system that considers influencing factors and evaluation goals. The initial system consisted of 17 initial evaluation indicators, which were revised and improved following interviews and surveys with experts. Finally, we created a comprehensive vulnerability assessment index for urban seismic activity (Table 1) consisting of 13 evaluation indicators in the four criteria categories of building vulnerability, secondary disaster risk, socioeconomic vulnerability, and urban emergency response capabilities [45-49].

The vulnerability of buildings is largely a reflection of a city's exposure to earthquakes. Casualties and property losses caused by the collapse of buildings account for most of the total losses of an earthquake. The risk of secondary disasters, which include floods, fires, pollutant leakages, and landslides, mainly reflects the sensitivity of a city to an earthquake, which often causes losses that are several-fold higher than the initial earthquake. Compared with rural areas, secondary disasters and induced seismicity in urban areas are more serious. Socioeconomic vulnerability also reflects the sensitivity of a city to an earthquake and refers to the likelihood of seismic activity causing long-term damage such as social and psychological burdens as well as paralysis of the economic structure. It is mainly connected to the overall density of the urban population, the distribution of vulnerable populations, and the pattern of urban economic strength. Urban emergency response capabilities are mainly related to a city's own defense and resilience after an earthquake to meet the needs of residents for postdisaster emergency relief as well as rescue and treatment.

(2) Use AHP to calculate indicator weights: The relationship between the factors in the evaluation system is analyzed to establish a systematic hierarchical structure and compare the importance of each pair, and a consistency test is conducted to obtain the indicator weights of experts. To make the index weights of urban seismic vulnerability evaluation indicators even more rational, this study invited three experts in the fields of natural disasters, urban planning and management, and construction engineering safety to undergo interviews and provide scores, and the average weights of the three experts were used as the final weights (Table 1).

(3) Standardize the element values using the SAVEE algorithm: To assess the seismic vulnerability of Hefei, the SAVEE algorithm can be used to perform different standardized equation calculations on various types of seismic vulnerability influencing factors. For negative seismic vulnerability factors that increase as $x$ 
TABLE 1: Seismic vulnerability evaluation index.

\begin{tabular}{|c|c|c|c|}
\hline Objective & Criteria & Factor & Weight \\
\hline \multirow{13}{*}{ Evaluation of urban earthquake vulnerability } & \multirow{3}{*}{$\begin{array}{l}\text { Building vulnerability } \\
\qquad 0.3300\end{array}$} & Building age & 0.0646 \\
\hline & & Building structure & 0.1628 \\
\hline & & Building height & 0.1026 \\
\hline & \multirow{4}{*}{$\begin{array}{l}\text { Secondary disaster risk } \\
0.3300\end{array}$} & Flood risk & 0.0982 \\
\hline & & Fire risk & 0.0927 \\
\hline & & Pollution leakage risk & 0.0581 \\
\hline & & Landslide risk & 0.0810 \\
\hline & \multirow{3}{*}{$\begin{array}{l}\text { Socioeconomic vulnerability } \\
0.1404\end{array}$} & Population distribution & 0.0436 \\
\hline & & Vulnerable pop. dist. & 0.0693 \\
\hline & & Economic strength & 0.0275 \\
\hline & \multirow{3}{*}{$\begin{array}{c}\text { Emergency response capability } \\
0.1996\end{array}$} & Fire station coverage & 0.0499 \\
\hline & & Hospital coverage & 0.0499 \\
\hline & & Shelter coverage & 0.0998 \\
\hline
\end{tabular}

increases, such as the coverage of fire stations, hospitals, and shelters, the standard calculation is carried out using formula (5), and the boundary value $(A)$ is $1000 \mathrm{~m}$. Positive vulnerability factors that increase as $x$ increases, such as population distribution density, vulnerable population distribution, building age, and building height, are calculated using formula (6), and the boundary value is $2000 \mathrm{~m}$. For positive vulnerability factors that decrease as $x$ increases, such as flood risk, fire risk, and pollution leakage risk, formula (7) is used, and the boundary value is $2000 \mathrm{~m}$. For negative vulnerability factors that decrease as $x$ increases, formula (8) is used. The formula for the SAVEE algorithm is as follows:

$V=-\left[\exp \left(\frac{-(x+1)}{|A|}\right)\right]^{5}, \quad x \leq A,-1 \leq V \leq 0$,

$V=1-\left[\exp \left(\frac{-(x+1)}{|A|}\right)\right]^{5}, \quad x \leq A, 0 \leq V \leq 1$,

$V=\left[\exp \left(\frac{-(x+1)}{|A|}\right)\right]^{5}, \quad x \leq A, 0 \leq V \leq 1$,

$V=\left[\exp \left(\frac{-(x+1)}{|A|}\right)\right]^{5}-1, \quad x \leq A,-1 \leq V \leq 0$

where in $V$ is the standardized value of seismic vulnerability; $x$ is the value of each influencing factor, and $\mathrm{A}$ is the boundary value.

(4) Calculate seismic vulnerability with the EMYCIN model: EMYCIN is an extension of reasoning under uncertainty based on the concepts and methods of probability theory. Based on evaluation data from the SAVEE model, the iterative algorithm is used to calculate the various pairwise standardized seismic vulnerability driving factors, until all the factors are analyzed and the seismic vulnerability of the study area is obtained. This will provide a visualization of seismic vulnerability at the spatial level. The EMYCIN formula is as follows:

$$
\begin{aligned}
& I_{a b}=I_{a}+I_{b}-I_{a} \times I_{b}, \quad I_{a}>0, I_{b}>0, \\
& I_{a b}=I_{a}+I_{b}+I_{a} \times I_{b}, \quad I_{a}<0, I_{b}<0, \\
& I_{a b}=\frac{\left(I_{a}+I_{b}\right)}{\left(1-\min \left[\left|I_{a}\right|,\left|I_{b}\right|\right]\right)}, \quad \text { else. }
\end{aligned}
$$

$I_{a}$ and $I_{b}$ are the standardized values of seismic vulnerability of influencing factors $a$ and $b$, and $I_{a b}$ is the superimposed value of factors $a$ and $b$.

\section{Results}

Earthquake risk assessment has become an effective means of government disaster risk management and resilient city construction. In order to predict and analyze earthquake disasters more accurately, scholars have conducted a lot of discussions, mainly using expert scoring method, multivariate statistical method, geostatistics, time series analysis, fuzzy comprehensive evaluation method, gray system theory, analytic hierarchy process, complex system theory, backpropagation (BP) neural network, and other methods [22-28]. Geographic Information System (GIS) technology is widely used because it can objectively reflect the distribution characteristics of earthquake risk. However, how to choose a reasonable earthquake risk assessment model has become an urgent problem to be solved. In order to solve the abovementioned difficulties and shortcomings, this paper proposes a hybrid intelligence model from the perspective of possibility and vulnerability. The evaluation results and the superiority of the algorithm are as follows.

4.1. Predicting Seismic Probability. The rapid development of computer technology represented by machine learning provides new ideas for the detection of seismic events. The main content of machine learning research is to let the machine generate a model from the input data, that is, a learning algorithm, and the generated model can provide corresponding judgments when facing new data. Machine 
learning and seismic historical data can help us further improve the detection accuracy under the premise of existing computing capabilities and algorithms and maximize the capabilities of the algorithm. For example, Jiang and Ning (2019) will combine features selected by manual experience with support vector machines [50], and Liu et al. (2020) combined Taiwan array strategy with deep learning [51]. The combination of multiple algorithms is also a new idea. For example, Witsil and Johnson (2020) combined GAN with K-Means [52], and Mousavi et al. (2019) combined CNN with LSTM network [53]. Semisupervised and unsupervised learning can avoid problems such as insufficient manual labeled data sets. Therefore, this paper proposes the GA-PSO-BP neural network model, which combines historical seismic data and geological plate conditions to predict the possibility of earthquakes.

Given the accuracy of prediction results and the limited earthquake related data for downtown Hefei, this paper expanded the scope of its earthquake probability assessment to the Hefei metropolitan area. ArcGIS was used to create a $500 \mathrm{~m}^{*} 500 \mathrm{~m}$ fishnet that divided Hefei into 45,745 grids. Various data was extracted into the grids, which was imported into MATLAB as the initial sample for simulation and prediction using the GA-PSO-BP integrated algorithm. The prediction results of earthquake probability in the metropolitan and downtown urban areas of Hefei were depicted using ArcGIS (Figures 4(j) and 4(k)). The analysis results show the following: Areas within the city with high earthquake probability are mainly concentrated in Feidong County and Lujiang County, with a few also in Hefei City, Feixi County, and Chaohu City. The reasons for their higher seismic probability are the high density of faults and epicenters, short distance to active faults and epicenters, poor geological stability, and complex topography. Areas of Changfeng County, Feixi County, and Chaohu City have lower earthquake probability. Of Hefei's main urban areas, the High-Tech Zone in the east, southern Shushan District, central Yaohai District, and northeastern Luyang District, as well as northern and southern parts of Xinzhan District, have a higher earthquake probability, whereas, Baohe District, the Economic Development Zone, the northern part of Shushan District, central Luyang District, and central Xinzhan District have lower earthquake probability.

Due to the advantages of the BP algorithm for solving nonlinear problems, GA was used to calculate the initial connection weights and thresholds, and PSO was used to optimize the connection weights and thresholds in each iteration, which eventually provided the seismic probability assessment result and algorithm efficiency for each grid in the Hefei metropolitan area. The performance index of neural network training is the average error between its predicted output value and the expected output value. The smaller the average error and the smaller the fitness value, the smaller the system error of the neural network. The GA model has the highest individual fitness value after 3 stop iterations. The GA-PSO-BP model has the lowest fitness after 25 stop iterations. The PSO model has 25 stop iterations, and its fitness is in between the other two (Figure 5(a)). Of the three earthquake probability prediction models, the
GA-PSO-BP model has the highest prediction accuracy, with a rate of $82.50 \%$; GA has a prediction accuracy rate of $81.25 \%$, and PSO has a prediction accuracy rate of $79.37 \%$ (Figure 5(b)). It can be seen that the GA-PSO-BP integrated model combines the advantages of multiple algorithms and benefits from fewer calculations, fast convergence, and good global convergence.

4.2. Assessing Seismic Vulnerability. The AHP-SAVEEEMYCIN is a method of reasoning under uncertainty that uses mathematical formulas and models to express various probabilistic reasoning. It can transform qualitative descriptions of influencing factors into quantitative values and combines the two in the assessment, making it useful in determining spatial imbalances in urban seismic vulnerability. The AHP method was used to determine the index system and weights. The SAVEE method standardized the impact factors of each type of seismic vulnerability (Figures 6(a)-6(m)), and pairwise iterations were performed using the iterative EMYCIN equation until all factors were in the calculation, which finally produced the results of the seismic vulnerability assessment for downtown Hefei (Figure 6(n)).

Areas with high seismic vulnerability are mainly concentrated in the old city, the area around Hefei West Railway Station, the government affairs district, Science City, and the East New Center. They are also distributed on a small scale in Xinzhan District, Gangji Town Industrial District, the Economic Development Zone, and Binhu New District outside the city's second ring road. These are areas of Hefei with more complex social and economic activities, higher building-related risks, more secondary disasters, and higher sensitivity and exposure to earthquakes. Low fire risk areas include Shushan Park, the Economic Development Zone, Science City, and the disused Luogang Airport, which are mainly used for scientific research and ecological and recreational functions, and their seismic vulnerability is low.

4.3. Assessing Overall Seismic Risk. Seismic risk is a combination of the probability of an earthquake and the effect of an earthquake that exceeds the safety threshold that a city can bear. Using ArcGIS, the seismic probability and vulnerability were superimposed after being standardized, and the composite result of the two provided overall seismic risk results (Figure 7(a)). Areas with high, higher, lower, and low seismic risk in Hefei accounted for $8.10 \%, 31.90 \%$, 40.94\%, and $19.06 \%$ of its total area, respectively. High risk areas are mainly concentrated in the old city, government affairs district, Science City, and Xinzhan District. These areas are closer to the seismic belt and are more vulnerable to earthquake damage. Low and lower risk areas include the disused Luogang Airport, the urban periphery, Gangji Town, Hefei Station, and Science City.

To investigate the differences in seismic risk in various areas of downtown Hefei, statistical analysis was carried out to determine the proportions of various levels of risk by land area and the proportions of various levels of risk by building 


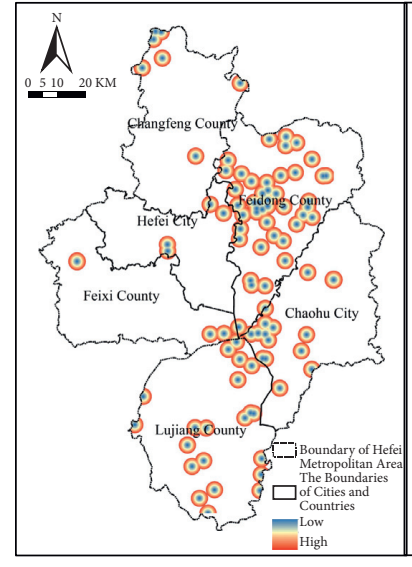

(a)

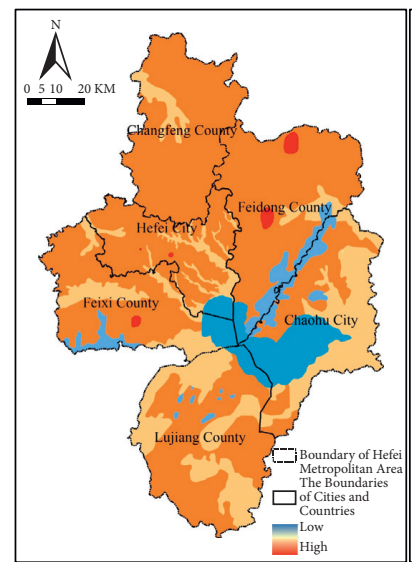

(e)

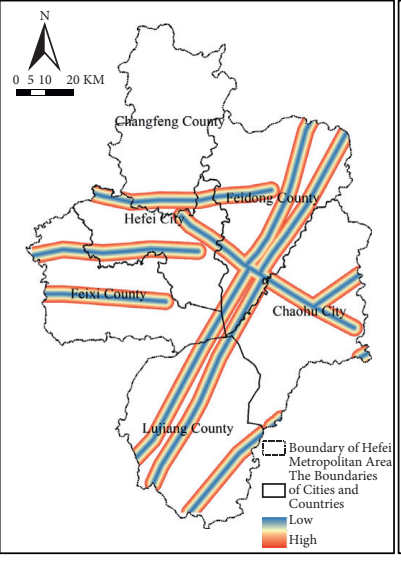

(b)

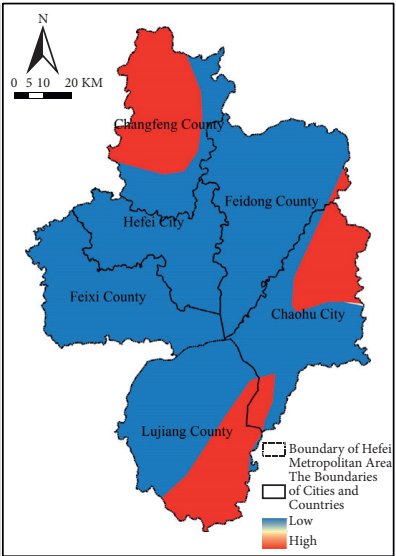

(f)

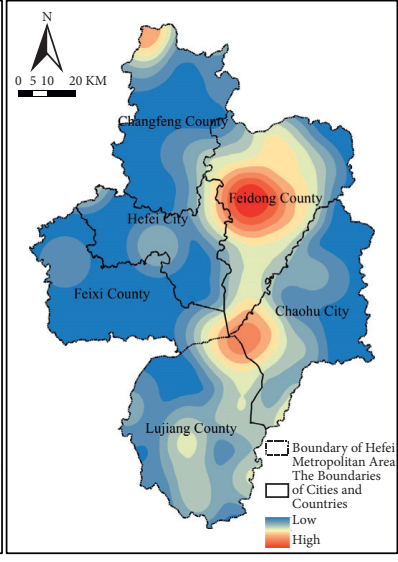

(c)

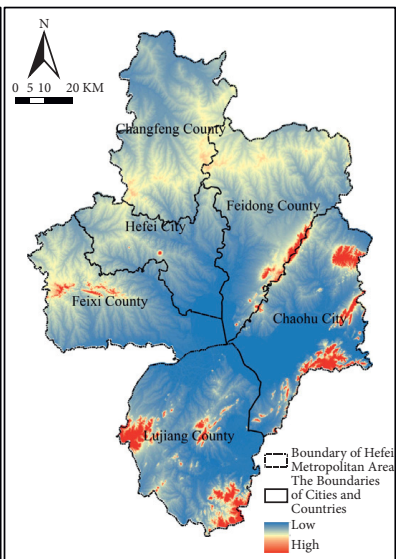

(g)

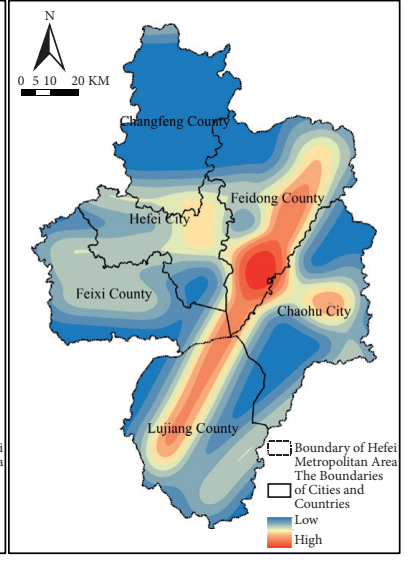

(d)

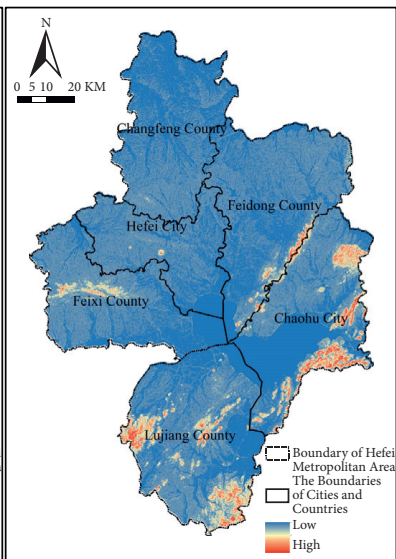

(h)

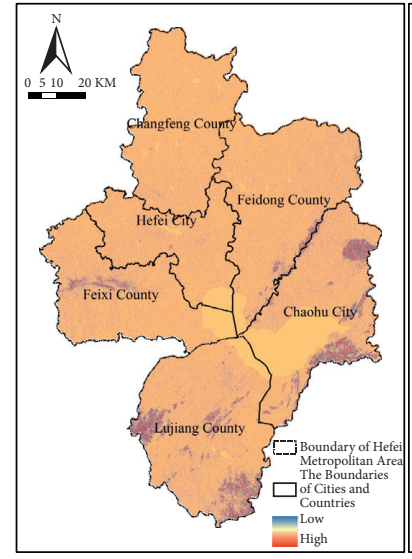

(i)

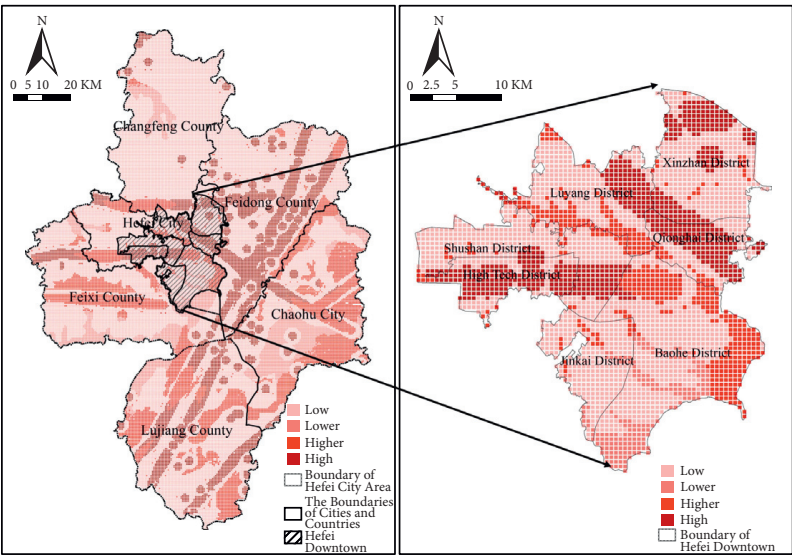

(k)

FIgURE 4: Predicting seismic probability. (a) Distance to epicenter. (b) Distance to fault zone. (c) Earthquake density. (d) Fault zone density. (e) Rock and soil stability. (f) Peak ground acceleration. (g) Elevation. (h) Slope. (i) Tortuosity. (j) Probability of earthquake in Hefei metro area. (k) Probability of earthquake in downtown Hefei.

area (Figures 7(b) and 7(c)). The area proportions reflect the overall seismic risk levels of each geographical area. The High-Tech Zone and Luyang District have the largest proportions of high risk areas, followed by Luyang District, Shushan District, and Xinzhan District, whereas, the Economic Development Zone and Baohe District have the smallest proportions. The Economic Development Zone has the lowest overall seismic risk, and Yaohai District and the High-Tech Zone have the highest overall seismic risk. The proportions of risk by building area reflect the level of seismic risk to a district's social and economic activities. The High-Tech Zone and Yaohai District have the largest proportions of high risk areas, followed by Luyang District, Shushan District, and Xinzhan District. The Economic Development Zone and Baohe District have the smallest proportions of high risk areas. The Economic Development Zone has the lowest building earthquake risk, and Yaohai District has the highest building earthquake risk. 


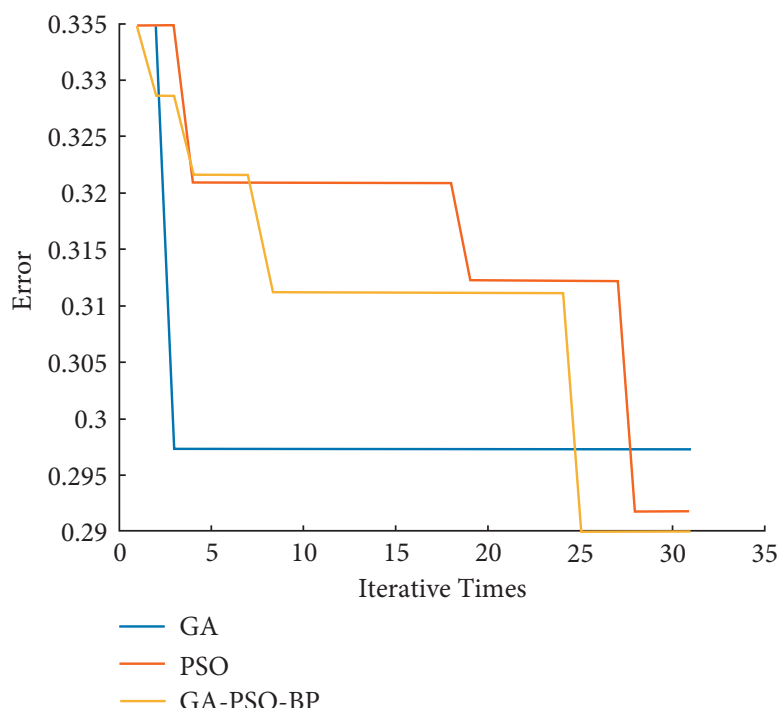

(a)

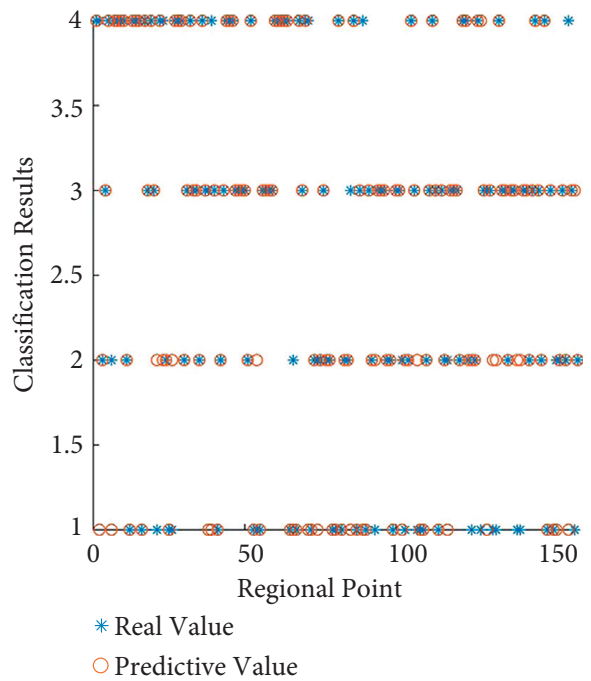

(b)

Figure 5: Algorithm efficiency. (a) Comparison chart of predictive values and real values. (b) Fitness curves of different models.

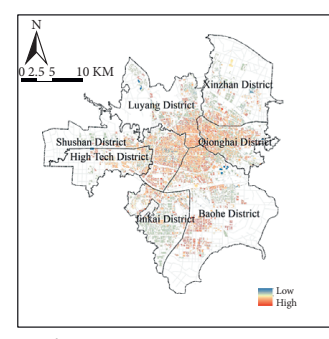

(a)

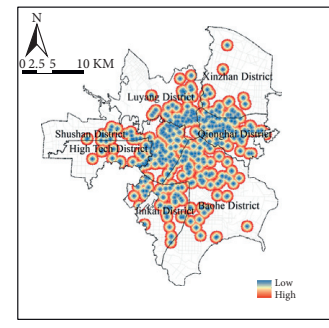

- Rosd

(f)

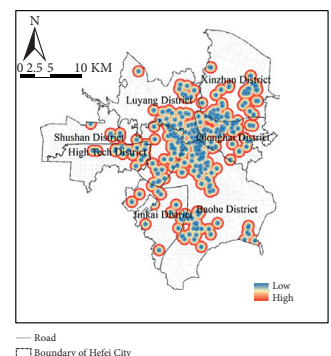

(k)

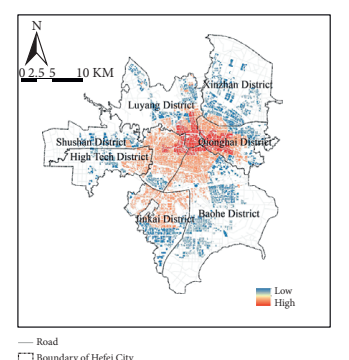

(b)

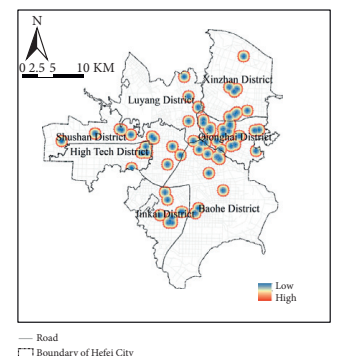

(g)

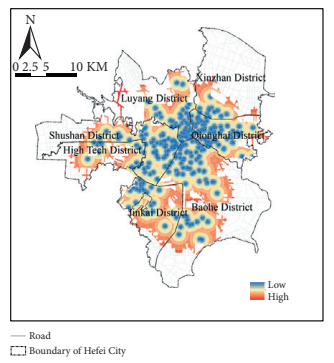

(1)

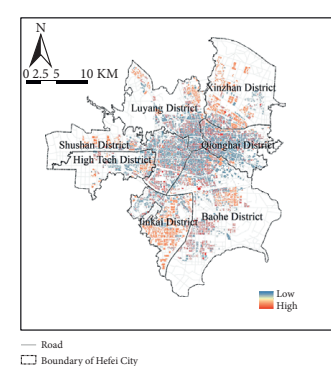

(c)

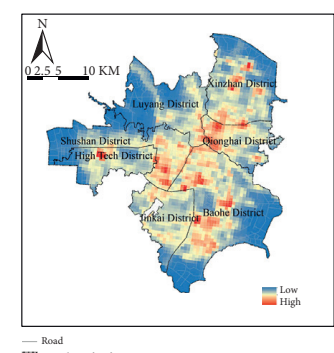

(h)

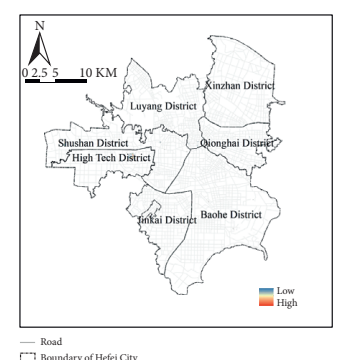

(d)

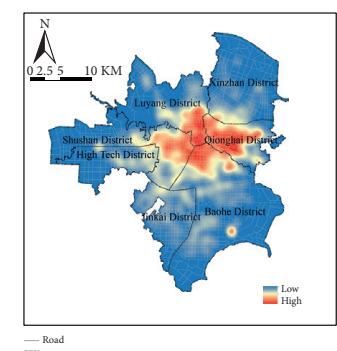

(i)

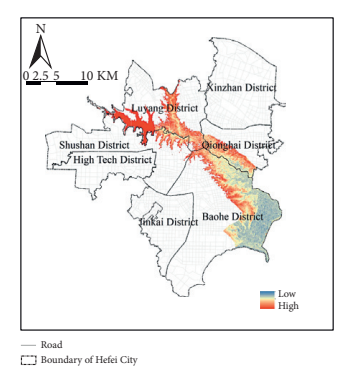

(e)

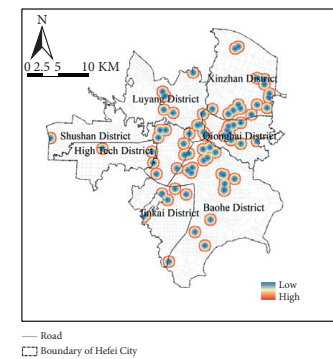

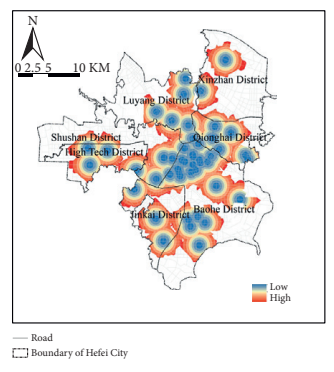

(m) (j)

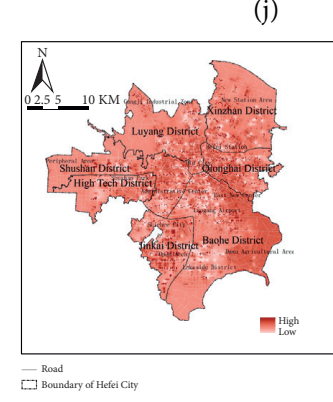

(n)

Figure 6: Assessing seismic vulnerability. (a) Building height. (b) Building age. (c) Building structure. (d) Landslide. (e) Flood. (f) Fire. (g) Pollution leakage. (h) Economic strength. (i) Population distribution. (j) Vulnerable population. (k) Shelter coverage. (l) Hospital coverage. (m) Fire station coverage. (n) Seismic vulnerability. 


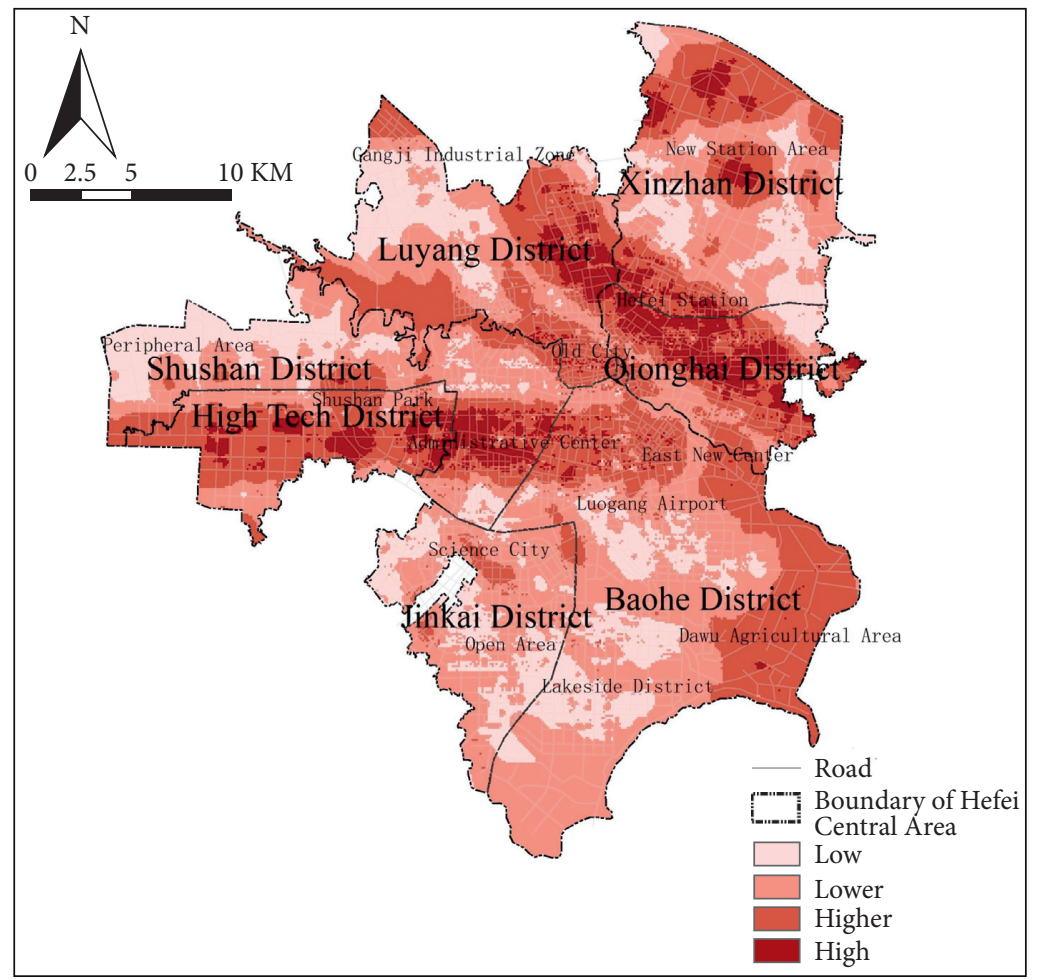

(a)

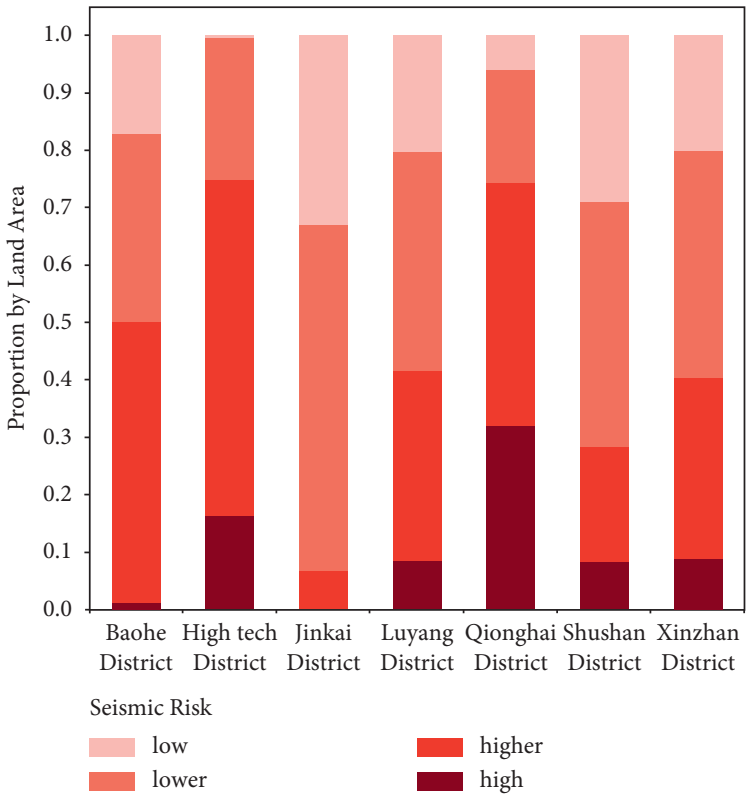

(b)

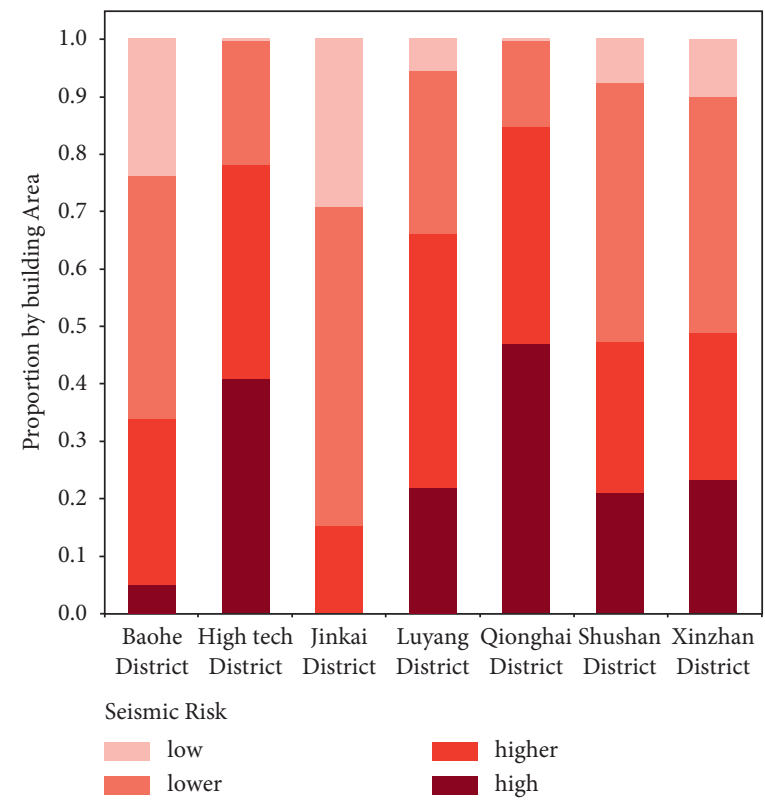

(c)

Figure 7: Assessing overall seismic risk. (a) Distribution of seismic risk. (b) Proportions by land area. (c) Proportions by building area.

Comparative analysis of the proportions of various risk levels by land area and building area shows that the HighTech Zone and Yaohai District have high proportions of high risk districts by land area and by building area, so earthquake risk prevention measures in those districts should be strengthened to reduce potential losses caused by earthquakes. Hefei's future development should be concentrated in areas with lower seismic risk.

\section{Discussion}

5.1. Innovation and Application Scope of Urban Earthquake Risk Assessment Model. Established under the existing evaluation system in the disciplines of disaster science, construction engineering, and urban management, the hybrid intelligent model integrates the perspectives and advantages of multiple disciplines [22-24]. This model is 
more suited and adaptable to the complex nonlinearity of earthquakes. The hybrid intelligent model includes three parts: a GA-PSO-BP integrated algorithm to predict the probability of earthquakes; an AHP-SAVEE-EMYCIN integrated algorithm to measure urban vulnerability during earthquakes, and an assessment of overall seismic risk after earthquakes occur. (1) The GA-PSO-BP algorithm used GA to determine the initial parameters of the BP network and used PSO to change the connection weights and thresholds in the training iterations, thereby speeding up the convergence of the network and avoiding falling into the local optimal solution. GA-PSO-BP automatically generated laws from inputted data on known earthquake events, and the possibility of earthquakes in other areas was predicted based on quantitative analysis of those laws as well as statistics and probability theory, which avoided errors caused by human predictions of seismic events. (2) The AHP-SAVEE-EMYCIN algorithm used the AHP method to establish an evaluation system and index weights. The SAVEE algorithm standardized the value of the impact factors, and the EMYCIN iterative calculation superimposed the roles of various factors to obtain seismic vulnerability. The AHP-SAVEE-EMYCIN is a method of reasoning under uncertainty that uses mathematical formulas and models to express various probabilistic reasoning. It can transform qualitative descriptions of influencing factors into quantitative values and combines the two in the assessment, making it useful in determining spatial imbalances in urban seismic vulnerability. (3) In the next step, earthquake probability and vulnerability were unified and standardized using ArcGIS and then superimposed to obtain a composite result of the two, namely, overall seismic risk, which can provide new ideas for seismic risk assessment and urban earthquake prevention and management.

The hybrid intelligent model focuses on measuring a relative value of risk and comparing the spatial distribution characteristics of earthquake risk in different areas of cities, to guide government prioritization of disaster prevention and mitigation measures. This model is not only suited to assessing seismic risk in Hefei. The parameters of the intelligent model and its related weights can be adjusted according to the characteristics of a study area and the differentiation of a problem so that it is suitable for areas and cities with similar conditions.

\subsection{Strengthen the Innovation of Cloud and Fog Computing in} Earthquake Risk Assessment. From an analytical point of view, the hybrid intelligence still has limitations, including the need for high-quality data, a time-consuming process, and the need for the integrated model to perform a large volume of probability mapping training data points. Seismology is a data-driven science, and research progress and breakthroughs often come from observations by seismic stations [27, 28]. In addition, the basic data in the existing seismic business system has a wide variety and huge amount, and the model and the organization relationship between the models are complicated. The establishment of an earthquake disaster loss assessment system requires the purchase and establishment of a spatial geographic database and an earthquake basic data database and the development of corresponding technical systems to achieve other specific functions. In recent years, the development of cloud computing and fog computing can solve the waste and idleness of a large number of resources caused by repeated construction.

According to the definition of the National Institute of Standards and Technology (NIST), cloud computing is a computing model that uses the Internet to realize anytime, anywhere, on-demand, and convenient access to a shared resource pool [54]. Through cloud computing and fog computing, users can quickly obtain services that meet their own business needs, improving service quality while reducing operation and maintenance costs. As a major innovation in the information industry, the cloud and fog computing have been widely recognized by industry and academia. Through cloud computing and fog computing, software and hardware resources and seismic information can be shared, providing various users with different levels of services, enabling users to quickly customize their own services on demand, thereby overcoming the problems of long construction period and high cost of seismic business systems in the past.

\subsection{Discussion on Strengthening the Seismic Risk Management} System under Different Scales. Existing research on earthquake risk measurement and quantification is affected by different disciplines, research object scales, historical disaster data, and index data availability, etc. The evaluation indicators are too simplified to select individual indicators to characterize or are limited to areas, engineering facilities, or the level of the building itself, without considering the interrelationship and influence between different scale factors [29]. In addition, in urban disaster risk research, the accuracy of small scale index data such as streets and communities will also affect the rigor of the final risk assessment results.

Factors of different scales do not exist independently but are interrelated and influenced and are related to the characteristic boundary of a specific area [30]. This paper constructs a multiscale evaluation system from the three aspects of Hefei's metropolitan area, downtown, and neighborhoods. Among them, the city scale mainly uses historical seismic data, topography, and geological plate conditions to construct earthquake probability prediction models; the central city scale and block scale are used to evaluate the vulnerability of the city, and the central scale includes the city's secondary disasters, social economic strength, and urban emergency response capabilities, etc.; block scale main design and building vulnerability conditions such as building height, structural strength, and construction year. This article only draws on the concept of multiscale from the perspective of earthquake risk assessment and should emphasize the multiscale coordinated management of disaster risk. 
In recent years, following the orderly advancement of China's urban agglomeration planning, metropolitan area strategy, regional integration, and other policies, the development of various cities and regions has become increasingly interwoven. Nevertheless, regional public crises often occur unexpectedly and can seriously damage the interests of society and individual citizens. Seismic fault zones often span multiple cities and even provinces, and differences in magnitude and focal depth of earthquakes mean that potential economic losses and social trauma are extremely difficult to estimate $[4,5]$. The complexity and interconnectivity of crises caused by earthquakes these days are increasing, so the degree of coordination between government and social entities has a direct bearing on the effectiveness of earthquake crisis management [55, 56]. Follow-up research can explore the diverse ways social entities can participate in governance from the perspective of disaster management at multiple scales, including clarifying rights and responsibilities, strengthening policies and regulations, and optimizing the development environment of social entities, to build empirical and efficient mechanisms for coordinating and governing diverse entities during regional public crises.

For Hefei, the case of this paper, the seismic risk results from the hybrid intelligent model can be combined to implement earthquake defenses in two areas: basic measures to mitigate urban earthquake damage and emergency measures before and after earthquakes. Basic measures include moving essential infrastructure, such as energy, transportation, and communication facilities, away from areas with higher seismic risk; improving earthquake resistance or proofing in areas with higher earthquake risk; developing areas with less harmful construction, including more open spaces and protecting ecological spaces; seismic reinforcement of new construction projects as well as seismic retrofitting of old structures; and ensuring the city develops with earthquake resistance and disaster prevention in mind. Emergency measures mainly consist of accommodating Hefei's existing conditions by adopting temporary remedial measures and rationally deploying and organizing disaster relief to reduce losses and casualties caused by earthquakes.

\section{Conclusions}

The preearthquake risk assessment to determine the possible scope and spatial distribution of the earthquake can effectively promote the disaster prevention and mitigation work of the city against the earthquake and its induced disasters. This article aims to develop a new urban earthquake risk assessment model and conduct an empirical study on Hefei. Combining the definition of risk and the attributes of natural disasters, through the composite result of earthquake probability and urban vulnerability, the earthquake risk is quantitatively described, and the spatial distribution of urban earthquake risk is obtained. Our main conclusions are as follows.

The GA-PSO-BP model has an accuracy rate of $82.5 \%$ in predicting the probability of earthquakes. The model has the advantages of fewer calculations, fast convergence, and good global convergence. The simulation results indicate that areas with higher earthquake probability within the municipal area of Hefei are mainly in Feidong County and Lujiang County, with a small number scattered throughout Hefei City, Feixi County, and Chaohu City. These areas have a higher probability because they are located near the seismic fault and plate stability is poor. The High-Tech Zone, southern Shushan District, central Yaohai District, northeast Luyang District, and northern and southern parts of Xinzhan District have a relatively high probability of seismic activity.

The AHP-SAVEE-EMYCIN method was used to evaluate vulnerability to earthquake damage from four aspects: building vulnerability, secondary disaster risk, socioeconomic vulnerability, and emergency response capabilities. Our research showed that areas with high seismic vulnerability are mainly concentrated in the old city, the area around the Hefei West Station, the government affairs district, Science City, and the Hefei East New Center. These are large areas of Hefei with complex social and economic activities, higher building risks, more secondary disasters, and higher sensitivity and exposure to earthquakes.

Earthquake probability and vulnerability were standardized and then superimposed, to obtain a composite result of the two, which we call overall seismic risk. The areas with very high, high, low, and very low overall seismic risk accounted for $8.10 \%, 31.90 \%, 40.94 \%$, and $19.06 \%$ of the total area of Hefei, respectively. Very high risk areas are mainly located in the old city, the government affairs district, Science City, and Xinzhan District. These areas are close to the seismic belt and are more vulnerable to earthquakes. In the future, targeted earthquake protection measures are required in the following two areas: basic measures to mitigate urban earthquake damage and emergency measures for before and after earthquakes.

\section{Data Availability}

The datasets used and/or analyzed during the current study are available from the corresponding author on reasonable request.

\section{Consent}

Not applicable.

\section{Conflicts of Interest}

The authors declare no conflicts of interest.

\section{Authors' Contributions}

Conceptualization was done by Q.Z. and A.W.; methodology was done by Q.Z., H.Y., and A.W; software was done by Q.Z. H.Y. and J.C.; writing-original draft preparation was done by Q.Z., J.C., and A.W.; writing-review and editing was done by Q.Z. and A.W. 


\section{Acknowledgments}

This research was funded by the National Natural Science Foundation of China (Grant no. 51678001); the Natural Science Foundation of Anhui Province (Grant no. 2008085QE241); Anhui Provincial University Natural Science Research Key Project (KJ2019A0752); Anhui Provincial Quality Engineering Project (2020yjsyljc035).

\section{References}

[1] H. Brecht, U. Deichmann, and G. H. A. Wang, Global Urban Risk Index. Policy Research Working Paper, The World Bank Publication, Washington D C, USA, 2013.

[2] S. Tesfamariam and M. Saatcioglu, "Seismic vulnerability assessment of reinforced concrete buildings using hierarchical fuzzy rule base modeling," Earthquake Spectra, vol. 26, no. 1, pp. 235-256, 2010.

[3] M. Ouyang, L. Dueñas-Osorio, and X. Min, "A three-stage resilience analysis framework for urban infrastructure systems," Structural Safety, vol. 36-37, pp. 23-31, 2012.

[4] V. Lambert, N. Lapusta, and S. Perry, "Propagation of large earthquakes as self-healing pulses or mild cracks," Nature, vol. 591, no. 7849, pp. 252-258, 2021.

[5] Y. Wang, Q. Lin, and P. Shi, "Spatial pattern and influencing factors of landslide casualty events," Journal of Geographical Sciences, vol. 28, no. 3, pp. 259-274, 2018.

[6] J. Yang, C. Cheng, C. Song, S. Shen, T. Zhang, and L. Ning, "Spatial-temporal distribution characteristics of global seismic clusters and associated spatial factors," Chinese Geographical Science, vol. 29, no. 4, pp. 614-625, 2019.

[7] S. Zhou, G. Zhai, Y. Shi, and Y. Lu, "Urban seismic risk assessment by integrating direct economic loss and loss of statistical life: an empirical study in Xiamen, China," International Journal of Environmental Research and Public Health, vol. 17, no. 21, p. 8154, 2020.

[8] Y. Liu, W. Zhang, Z. Zhang, Q. Xu, and W. Li, "Risk factor detection and landslide susceptibility mapping using geo-detector and random forest models: the 2018 hokkaido eastern $\mathrm{i}$ earthquake," Remote Sensing, vol. 13, no. 6, p. 1157, 2021.

[9] J. Gomberg, P. A. Reasenberg, P. Bodin, and R. A. Harris, "Earthquake triggering by seismic waves following the Landers and Hector Mine earthquakes," Nature, vol. 411, no. 6836, pp. 462-466, 2001.

[10] M. T. Page, N. Van der Elst, T. H. Jordan, A. J. Michael, B. E. Shaw, and M. J. Werner, "A spatiotemporal clustering model for the third uniform California earthquake rupture forecast (UCERF3-ETAS): toward an operational earthquake forecast," Bulletin of the Seismological Society of America, vol. 107, no. 3, pp. 1049-1081, 2017.

[11] E. H. Field, T. E. Dawson, K. R. Felzer, and A. D. Frankel, "Uniform California earthquake rupture forecast, version 2 (UCERF 2)," Bulletin of the Seismological Society of America, vol. 99, no. 4, 2009.

[12] P. Wang, Z. Shao, Q. Liu, W. X. Wei, and X. F. Yin, "Probabilistic forecasting of earthquakes based on multidisciplinary physical observations and its application in Sichuan and Yunnan," Chinese Journal of Geophysics, vol. 62, no. 9, pp. 3448-3463, 2019.

[13] S. A. Khan, K. Pilakoutas, I. Hajirasouliha, and R. Garcia, "Seismic risk assessment for developing countries: Pakistan as a case study," Earthquake Engineering and Engineering Vibration, vol. 17, 2018.
[14] J. R. Murray, J. O. Langbein, S. E. Owen, T. H. Heaton, R. A. Iannucci, and D. L. Hauser, "Crowdsourced earthquake early warning," Science Advances, vol. 1, no. 3, Article ID e1500036, 2015.

[15] A. S. N Alarifi, N. S. N. Alarifi, and S. Al-Humidan, "Earthquakes magnitude predication using artificial neural network in northern Red Sea area," Journal of UniversityScience, vol. 24, no. 4, pp. 301-313, 2012.

[16] T. Rashed and J. Weeks, "Assessing vulnerability to earthquake hazards through spatial multicriteria analysis of urban areas," International Journal of Geographical Information Science, vol. 17, no. 6, pp. 547-576, 2003.

[17] J. Han, A. Nur, M. Syifa, M. Ha, and C. Lee, "Improvement of earthquake risk awareness and seismic literacy of Korean citizens through earthquake vulnerability map from the 2017 pohang earthquake, South Korea," Remote Sensing, vol. 13, no. 7, p. 1365, 2021.

[18] G. Noriega and L. Ludwig, "Social vulnerability assessment for mitigation of local earthquake risk in Los Angeles County," Natural Hazards, vol. 64, no. 2, pp. 1341-1355, 2012.

[19] J. Joseph, "Measuring vulnerability to natural hazards: a macro framework," Disasters, vol. 37, no. 2, pp. 185-200, 2013.

[20] S. Khan, "Vulnerability assessments and their planning implications: a case study of the Hutt Valley, New Zealand," Natural Hazards, vol. 64, no. 2, pp. 1587-1607, 2012.

[21] A. Mosen, N. Ibrahim, H. Mazlan, and P. Biswajeet, "A hybrid analytic network process and artificial neural network (ANPANN) model for urban earthquake vulnerability assessment," Remote Sensing, vol. 10, no. 6, p. 975, 2018.

[22] U. N. E. P. Global, Outlook 3: Past, Present and Future Perspectives, Earthscan Publications Ltd., London, UK, 2002.

[23] UNISDR, Terminology on Disaster Risk Reduction, UN Publications, Geneva, Switzerland, 2009.

[24] G. D. Bathrellos, H. D. Skilodimou, K. Chousianitis, A. M. Youssef, and B. Pradhan, "Suitability estimation for urban development using multi-hazard assessment map," Science of The Total Environment, vol. 575, pp. 119-134, 2017.

[25] Z. Zhong and J. Yu, "Prediction of earthquake damages and reliability analysis using fuzzy sets," in Proceedings of the International Symposium on Uncertainty Modeling \& Analysis. IEEE, College Park, MD, USA, December 1990.

[26] R. Davidson and H. C. Shah, "A multidisciplinary urban earthquake disaster risk index EERI annual student paper award a multidisciplinary urban earthquake disaster risk index," Earthquake Spectra, vol. 13, no. , 2, pp. 211-223, 1997.

[27] R. Jena, B. Pradhan, G. Beydoun et al., "Integrated model for earthquake risk assessment using neural network and analytic hierarchy process: Aceh province, Indonesia," Geoscience Frontiers, vol. 11, no. 2, pp. 613-634, 2020.

[28] R. Robat Mili, K. Amini Hosseini, and Y. O. Y. Izadkhah, "Developing a holistic model for earthquake risk assessment and disaster management interventions in urban fabrics," International Journal of Disaster Risk Reduction, vol. 27, pp. 355-365, 2018.

[29] S. Curceac, P. M. Atkinson, A. Milne, L. Wu, and P. Harris, "An evaluation of automated GPD threshold selection methods for hydrological extremes across different scales," Journal of Hydrology, vol. 585, 2020.

[30] B. Yatsalo, T. Sullivan, V. Didenko, and I. Linkov, "Environmental risk management for radiological accidents: integrating risk assessment and decision analysis for remediation at different spatial scales," Integrated Environmental Assessment and Management, vol. 7, no. 3, 2011. 
[31] A. Wang, Q. Zhang, L. Lu, H. R. Yu, and C. W. Huang, "Urban fire risk assessment and planning response based on multisource data," Science Journal, vol. 31, no. 3, pp. 148-155, 2021, in chinese.

[32] F. Nie, Y. Shi, Z. Zhang, and J. Wang, "The initial time of the Tan-Lu wrench fault: In the view of geochronological data of the basement rocks, northern Anhui Province," Chinese Science Bulletin, vol. 60, pp. 2315-2326, 2015.

[33] Y. Li, S. Wu, W. Han, and Y. Zhang, "A study on geophysical features of deep structures of the Hefei Basin and the southern Tan-Lu fault zone," Chinese Journal of Geophysics, vol. 49, no. 1, pp. 115-122, 2006.

[34] T. Uchide, "Focal mechanisms of small earthquakes beneath the Japanese islands based on first-motion polarities picked using deep learning," Geophysical Journal International, vol. 223, no. 3, pp. 1658-1671, 2020.

[35] D. E. Rumelhart, G. E. Hinton, and R. J. Williams, "Learning representations by back-propagating errors," Nature, vol. 323, no. 6088, pp. 533-536, 1986.

[36] J. H Holland, Adaptation in Natural and Artificial Systems: An Introductory Analysis with Applications to Biology, Control, and Artificial Intelligence, University of Michigan Press, Ann Arbor, MI, USA, 1975.

[37] J. Kennedy and R. Eberhart, "Particle swarm optimization," International Proceedings of the IEEE International Conference on Neural Networks, vol. 4, no. 2, pp. 1942-1948, 1995.

[38] A. Huo, H. Zhang, L. Zhang, and M. Hou, "A sampled method of classification of susceptibility evaluation unit for geological hazards based on GIS," Applied Mathematics \& Information Sciences, vol. 6, pp. 19-23, 2012.

[39] E. Zebardast, "Constructing a social vulnerability index to earthquake hazards using a hybrid factor analysis and analytic network process (F'ANP) modelConstructing a social vulnerability index to earthquake hazards using a hybrid factor analysis and analytic network process (F'ANP) model," Natural Hazards, vol. 65, no. 3, pp. 1331-1359, 2013.

[40] L. Chen, W. Wang, and W. Zhang, "Risk evaluation of regional collapses geological hazard based on DS evidence theory-a case study of Haiyuan active fault belt in Ningxia Province," Energy Procedia, vol. 16, pp. 371-376, 2012.

[41] M. W. Van, E. H. Shortliffe, and B. Buchanan, EMY-IN: A Knowledge Engineer's Tool for Constructing Rule-Based Expert Systems, pp. 249-263, Pergamon- Infotech State of the Art Report on Machine Intelligence, Maidenhead, UK, 1981.

[42] M. Panahi, F. Rezaiee, and S. A. Meshkani, "Seismic vulnerability assessment of school buildings in Tehran city based on AHP and GIS," Natural Hazards and Earth System Sciences, vol. 1, no. 5, pp. 4511-4538, 2014.

[43] D. K. Loh and Y. T. C. Hsieh, AI Applications: Natural Resources, Agriculture and no. 1, , pp. 29-40.

[44] D. K. Loh, D. R. Holtfrerich, and S. E. P. Van Stipdonk, "Automated construction of rulebases for forest resource planning," Computers and Electronics in Agriculture, vol. 21, no. 2, pp. 117-133, 1998.

[45] D. F. D'Ayala, A. Carriero, F. Sabbadini et al., "Seismic vulnerability and risk assessment of cultural heritage buildings in istanbul, Turkey," in Proceedings of the 14th WCEE, vol. 3, Beijing, China, January 2008.

[46] W. Yang, X. Zhang, and P. Luo, "Transferability of convolutional neural network models for identifying damaged buildings due to earthquake," Remote Sensing, vol. 13, no. 3, p. 504, 2021.
[47] P. Guerrero-Miranda and A. G. González, "Responsibility, Social responsibility, sustainability, and public policy: the lessons of debris management after the manabí earthquake in Ecuador," International Journal of Environmental Research and Public Health, vol. 18, no. 7, p. 3494, 2021.

[48] J. Yin, S. Xu, Y. Jing, Z. Yin, and B. Liao, "Evaluating the impact of fluvial flooding on emergency responses accessibility for a mega-city's public services: a case study of emergency medical service," Journal of Geographical Sciences, vol. 73, no. 9, pp. 1737-1747, 2018.

[49] L. Ceferino, J. Mitrani-Reiser, A. Kiremidjian, G. Deierlein, and C. Bambarén, "Effective plans for hospital system response to earthquake emergencies," Nature Communications, vol. 11, no. 1, p. 4325, 2020.

[50] Y. R. Jiang and J. Y. Ning, "Automatic decision of semic bodywave phases and dermination of their arrival times based on support vector machine," Chinese Journal of Geophysics, vol. 62, no. 1, pp. 361-373, 2019, in Chinese.

[51] F. Liu, Y. Jiang, J. Ning, J. Zhang, and Y. Zhao, "An arrayassisted deep learning approach to seismic phase-picking," Chinese Science Bulletin, vol. 65, no. 11, pp. 1016-1026, 2020.

[52] A. J. C. Witsil and J. B. Johnson, "Analyzing continuous infrasound from Stromboli volcano, Italy using unsupervised machine learning," Computers \& Geosciences, vol. 140, Article ID 104494, 2020.

[53] S. M. Mousavi, W. Zhu, Y. Sheng, and G. C. Beroza, "CRED: a deep residual network of convolutional and recurrent units for earthquake signal detection," Scientific Reports, vol. 9, no. $1,2019$.

[54] P. Mell and T. Grance, The NIST Definition of Cloud Computing, National Institute of Standards and Technology, Gaithersburg, MD, USA, 2011.

[55] W. M. P. Klein, A. K. Boutté, H. Brake et al., "Leveraging risk communication science across US federal agencies," Nature Human Behaviour, vol. 5, no. 4, pp. 411-413, 2021.

[56] D. Lee, "The expertise of public officials and collaborative disaster management," International Journal of Disaster Risk Reduction, vol. 50, no. 6, Article ID 101711, 2020. 